\title{
LITERATURE FOR THE TWENTY-FIRST CENTURY Developing Multimodality and Entrepreneurial Skills Through Literature-based Assessments
}

\author{
Melissa Shamini Perry \\ Universiti Kebangsaan Malaysia \\ mel@ukm.edu.my
}

\begin{abstract}
Since the twentieth century, the teaching and learning of literature have primarily focused on developing language, communication, and to some extent, critical thinking skills. Literary texts are included in education curricula with the primary intention that they help students develop good listening, speaking, reading, and writing skills. As a result, assessments in literary studies have also focused on testing language proficiency such as comprehension, vocabulary, and grammar. This has led to the misconception that in the multimodal, digital twenty-first century environment, the study of literature has little to offer beyond language development. This article aims to demonstrate that in addition to language and communication skills, literary studies can also be used to develop multimodal literacies and entrepreneurial skills such as creativity, leadership, reflective thinking, problem solving, and collaboration which are all highly valued in the twenty-first century. Through detailed explication of an innovative, alternative assessment for a literature course offered at The National University of Malaysia, this study showcases how multimodal literacy and entrepreneurial skills are developed through literary studies. This study presents the wide-ranging potential of literary studies and how, with the use of the creative and innovative teaching and assessment approaches, literature can remain valuable and relevant in the twenty-first century.
\end{abstract}

\section{Keywords}

literary; twenty-first century; alternative assessments; multimodal; entrepreneurial skills

\section{About the Author}

Melissa Shamini Perry is a senior lecturer at the Faculty of Social Sciences and Humanities at The National University of Malaysia. She teaches Literature in English and adopts a holistic and multimodal approach to teaching and learning. Her research interests are in the area of multimodality, literature, media, culture, and multiculturalism. 


\section{INTRODUCTION}

The twenty-first century demands that individuals engage with multimodal communication and employ multiple intelligences and skills in every life domain. As a result of changing mind-sets, expectations, and transformations in the ways of living, learning, working, and communicating, more skills are needed in order to remain relevant and productive. While the knowledge and skills deemed important in the twentieth century such as communication, general knowledge, critical thinking, and leadership skills remain significant, other skills such as creativity, problem solving, rapid skills acquisition, technology literacy, collaborative communication, cultural awareness, and social responsibility have emerged as skills and attributes sought after in individuals to meet the demands of a dynamic, globalized, and technology driven world (Griffin and Care 1-2).

In order to be competent and to function competitively in the twenty-first century, students must be equipped with the right sets of skills. Among the most sought-after skills in the employment market today are entrepreneurial skills (Boyles 44). Skills and attributes that are considered to be entrepreneurial in the twenty-first century include creativity, critical thinking, reflective thinking, problem solving, communication, digital literacy, and leadership skills (Boyles 45). Among these, creativity is considered to be among the most important attributes for an entrepreneur (Boyles 43). As reported by Boyles, in the United States of America, "companies rank leadership, critical thinking and creativity among the highest rated desired skills of new employees" (43). Similarly, in Malaysia, employers cite communication, creative/critical thinking, and analytical and problemsolving competencies as being important skills required in hiring graduates from Malaysian universities (Talentcorp). Such findings across the globe have challenged educational institutions and educators to rethink and revise tertiary level education so that the courses and programs develop twenty-first century knowledge, skills, and abilities in students and effectively prepare them for the demanding job market (Boyles 42). Thus, entrepreneurial skills and mind-sets are not just vital for potential entrepreneurs, but also for all students and individuals who want to be effective and successful in the twenty-first century.

In keeping with rapid advancements specifically in technology and communication in the twenty-first century, fields of studies are evolving and growing. New discoveries, inventions, and technology are changing the way people acquire and apply knowledge and information. As such, the teaching and learning methods and approaches for both the sciences and humanities subjects have to keep up with the changing trends and methods. This is so that students are equipped with the right set of skills and are considered as valuable, multi-skilled, and relevant individuals in society. 
In many tertiary educational institutions, those in the sciences have been quicker in adopting more current and updated approaches in their field of study than those in the arts and humanities departments. This is due to the need to stay abreast with the latest technology and equipment so that the students do not end up with knowledge and skills that have become obsolete by the time they enter the workforce. In the humanities, the changes in the core body of knowledge, in departments such as language studies, literature and even history, for example, have not been as rapid as in the sciences although there have been developments and advancements in theories and methods. As a result, the humanities departments, with some exceptions, have remained largely traditional and in some cases even outdated in content development and approaches for teaching and learning (Bassnett 212). Literature as a subject of study has been becoming less popular since the mid-twentieth century and is in danger of becoming obsolete with the rising interest in the sciences, information, and digital technology in the twentyfirst century (Kramsch and Kramsch 553). Among the reasons for its decline are the changing interests and literacy skills of present-day learners and the outdated teaching methods that do not keep up with current trends and demands (Bassnett 212).

In a twenty-first century learning environment filled with digital natives who have high visual and technological literacy, literature classes seem to be stuck in the twentieth century by being too word/print-oriented although literary works themselves have developed in the visual, audio, and digital modes (Bassnet 211). Although the written word remains a significant and integral part of literary studies, the younger generations of learners today seek to engage in other forms of literacies that make up their daily communication today. As a result, literature has been regarded as an outdated, irrelevant, and even boring subject in comparison to more current and trendy subjects like visual informatics, gamification, and digital media literacy.

One of the chief concerns of students and parents alike is the value of literature in providing employable skills beyond those related to language development and communication (Dass 29o). The perception that literature is a subject that is elitist, irrelevant, and impractical is also among the reasons why students choose not to study literature (Kramsch and Kramsch 554). As noted by Roche, "the humanities are suffering from a crisis. Whereas society immediately recognizes the value of science and technology, the value of literature and the humanities is less apparent to many persons" (1). Hence, many students at the tertiary level do not see the value of literature beyond improving language proficiency and choose not to take literature courses even as an elective unless they want to improve their language proficiency. 
This perception that the study of literature is merely a tool to improve language proficiency stems from the experiences students have had in studying literature in the primary and secondary levels especially in Malaysia. This study demonstrates creative and alternative methods of assessment in literary studies that help develop students' skills beyond language and literacy including entrepreneurial skills such as creativity, critical thinking, and problem solving. The following sections include a brief discussion on the evolution of literary studies including past and conventional approaches employed in the teaching and assessments of literature classes in schools and tertiary institutions with a focus on the Malaysian context.

\section{TEACHING AND ASESSEMENTS IN LITERARY STUDIES}

In the education curriculum of many countries around the world, literature forms a component of language studies. In countries in the Asia Pacific region including Malaysia, "discussions about where English Literature should be situated within the curriculum have also tended to be connected to English as a Second or Foreign Language programmes, where Literature is often perceived as a tool for English language learning, rather than a subject to be studied in itself" (Chin, Choo, and Beavis 3). In such contexts, language proficiency is usually the ultimate goal of literature lessons and this has affected teaching and assessments methods in literature classrooms. Hence, teachers handle literature in English classes in a way that focuses on the linguistic mode to develop students' mastery of the English language. This leads to testing and assessments that focus on comprehension and vocabulary more than anything else. Thus, good grades in English Literature would be considered to indicate mastery of the English language. Such approaches also naturally affect learning styles for the subject where students are focused on getting perfect scores, memorizing texts, and regurgitating them during tests and exams. In the O Levels English literature paper, for example, there has been a strong emphasis on learning by rote style due to the learning of literature in British schools since the late nineteenth century which involves the memorization and recitation of poetry (The National Curriculum in England). In many Malaysian secondary schools and university literature tests in the present day, students are still being tested on their ability to recall literary texts by memory (Siti Nurliana et al. 53).

While such techniques may have suited the learning philosophies and goals in the past, they do little to engage and ignite students' passion towards the subject especially in the twenty-first century. As a result, many students view literature as a dull and boring subject and do not develop an interest and appreciation for it. There is therefore a need to revamp teaching and testing methods in the teaching 
and learning of literature to ignite in students and society interest and appreciation for literature and what it has to offer beyond language and linguistic literacy development for the twenty-first century generation.

\section{Teaching and Learning of Literature in English in Malaysia}

Literature in English in Malaysia was introduced as a compulsory component in the English Language (KOMSAS) subject in the Malaysian secondary education curriculum in 2000 (Director General of Education Malaysia). KOMSAS was introduced in the teaching of English as a second language in Malaysia in order to inculcate in students the love of reading and also to reinforce language skills including listening, speaking, reading, and writing skills (Director General of Education Malaysia). The literature component was then included in the national secondary school examinations for Year 9 (PMR) and Year 11 (SPM) students (Sidhu, Chan, and Kaur 56). In 2005, literature was introduced in Malaysian primary schools through the Contemporary Children's Literature (CCL) program in order to boost English language proficiency and encourage students to become avid and independent readers (Sidhu, Chan, and Kaur 56).

The focus of teaching of literature in Malaysian schools is very much keen on using literature as a tool to increase language proficiency. Consequently, assessments in literature classes test students on listening, speaking, reading, and writing skills. Research findings on the CCL program revealed that teachers spent a lot of time on language-based and comprehension activities that emphasized on reading and writing skills, with very little time given toward listening and speaking skills (Sidhu, Chan and Kaur 56). In their observations of the CCL literature classrooms in Malaysia, Sidhu, Chan and Kaur found that there was very little opportunity for students to develop higher order thinking skills such as critical thinking (57-58).

Literature classes in Malaysian secondary schools were found to be rather teacher-centered, and students were drilled to memorize facts, answer multiplechoice questions, and read aloud so that they were prepared for examinations (Siti Norliana et al. 53). Such methods are rather outdated and do not resonate with twenty-first century learners, who are digital natives and may not see the importance of memorizing texts that they can instantly access through their smart phones. There have been some attempts to update teaching materials and methods in the literature classroom so that it becomes contemporary and relevant to today's learners. These attempts include the updating of the selection of literary texts in the syllabus and the use of creative approaches and multimodal digital tools in teaching literature. 
Unfortunately, despite such efforts, assessment methods for literature remain unchanged in most cases (Jia 120). In school and national exams, students are still tested only in writing, reading, speaking, and listening skills. Under pressure to ensure students achieve good grades, teachers are forced to employ rote learning methods in order to prepare students for the written and oral exams. As a result, studies on students' attitudes toward the teaching methods revealed that students had negative experiences of learning literature (Siti Norliana et al. 55). At tertiary institutions, literature is also taught with a focus on language proficiency especially on reading, writing, vocabulary, and grammar (Sivapalan and Ganakumaran 55). Studies revealed that tertiary students viewed literature to be an irrelevant subject for undergraduate level and is useful only to develop language proficiency at preuniversity and foundation levels (Sivapalan and Ganakumaran 56-57).

Such findings on the teaching and learning methods for literature in Malaysia could provide an understanding of why there is little interest and passion for literary studies among Malaysian students, especially at the tertiary level. The experience that most Malaysians students have with literature is confined to what they experienced in the English language classrooms in schools. Outdated teaching methods and assessments that solely focus on reading, writing, and grammar have deprived Malaysians of the opportunity to develop an appreciation or even love for literature and all that it has to offer, not just in language proficiency but also in one's personal holistic education and national growth and development.

Fortunately, the teaching and learning of literature in Malaysia and around the world have been evolving to include more current trends and to develop skills and abilities beyond language competence. Even in societies which have a strong tradition of rote learning methods like Hong Kong, literature lecturers are avoiding rote learning methods and are assessing students based on originality and creativity in assignments (Sullivan 63). Such subtle changes in teaching and assessment methods are slowly changing students' perception of literary studies, prompting even non-literature or language majors to take literature courses as a minor or an elective. Over the last decade, as part of the Malaysian National Higher Education Action Plan 2007-2010, holistic programs that cut across disciplines were introduced to expose tertiary students to subjects beyond their areas of study (Sivapalan and Subramaniam, 47). Literature courses were among those offered to arts, humanities, and science majors at Malaysian universities. This, together with new teaching and assessment approaches in tertiary literature courses, has been instrumental in helping increase the appreciation of literature in developing essential student skills that will enable them to be successful individuals in the twenty-first century. The next section looks at current developments in literary studies and innovative and alternative approaches in the teaching and assessment of literature at the tertiary level. 


\section{CURRENT TRENDS AND APPROACHES IN LITERARY STUDIES}

As an academic field, literary studies continues to grow and broaden its scope and teaching methods to keep up with developments in technology and society. As noted by Bassnett, the future of literature and English studies "lies in the facing up to the changes in reading, in information gathering, in types of literacy and in seeking to provide students with useful tools for the future" (212). Therefore, while still keeping its focus centered on reading and comprehension skills with the aim of developing oral and verbal literacy, cultural awareness, and critical and creative thinking skills, literary studies has evolved and has also used digital technology, different media, and social media to develop visual, media, and technology literacy (Subramaniam 1-2; Periasamy, Gruba and Subramaniam 152). This is because the current generation of learners needs to be taught and assessed differently from the previous generations as they already have developed various skills and literacies at a much younger age.

According to Kramsch and Kramsch, "the electronic revolution is changing our students' understanding of fiction and reality, form and content, orality, literacy and visuality" (569). Bassnett explains that the current generation of learners "are visually literate and they can follow highly complex plot lines from their diet of soap operas and animated cartoons, they are more sophisticated potential readers" (211212). To inspire and enrich the minds of current students, literature teachers and lecturers have to use different tools and approaches than those used in the past. As noted in Lowden et al., "the establishment of new forms of assessments can begin a fundamental change" in education and the skills that are developed by "changing the way courses are taught" and the way students are assessed (10). It is therefore important that literature subjects and courses in schools and universities today teach and assess students in ways that help them develop multimodal literacies and skills that are relevant to the twenty-first century.

In recognition of the different needs and abilities of current students, more and more literature lecturers in tertiary institutions have begun to incorporate multiple modes of meaning and technology to further develop multimodal and digital literacy in students (Noraini 127; Pillai and Vengadasamy 133). Creative and alternative forms of assessments that develop various skills in addition to inculcating knowledge of literary texts and devices are being used to increase students' interest and enjoyment of literature courses. Bassnett cites an example of over-subscribed literature course on Chaucer taught by a lecturer in the United Kingdom, where students would produce a board game based on the text of the Wife of Bath's Tale (210). According to Bassnett, through the creative assessment, the students demonstrated detailed and intelligent reading of the text and secondary sources beyond what could have been shown in a traditional essay (210). 
At Malaysian universities too, there have been various attempts to use creative and innovative teaching and alternative assessment methods in literature courses. For example, Noraini used computer and technological programs in the composition of original and creative texts in E-Methods in Literary Production, a course taught to university students at The National University of Malaysia (127, 128). Various digital tools and media including PageMaker, FrontPage, and blogs were used in the teaching of literature (Noraini 129). Such innovative assessment methods demonstrate the incorporation of digital technology in creative literary productions and analyses. Students gain literary knowledge and creative skills and also develop digital knowledge and ICT skills in addition to the holistic life lessons and societal values that literary studies imparts.

Other literature courses at The National University of Malaysia (UKM) such as Literature and the Media; Critical Appreciation; Literature for Emotional Intelligence; Stories for Growth Mind-set; and Narratives, Global Trends and Everyday Culture that are offered as liberal arts courses for students from various faculties, use literary texts to develop a variety of skills beyond language such as visual and media literacy, digital skills, creative and critical thinking, emotional intelligence, reflective thinking, intercultural awareness, and teamwork. These courses use methods and assessments that employ creative and current teaching methods and alternative forms of assessments such as short film productions and premieres, merchandise design, creative designs and products, vlogs, docudramas, digital art, and social experiments that are attractive and relevant to the current generation of students.

As noted in Chin, Choo, and Beavis, creative productions are as a necessary part of Literature education and therefore, almost all literature courses at the UKM include creative productions as a major part of the course assessment (3). In the assessments of the above-mentioned courses, students are awarded marks based on originality, creativity, and critical thinking among other skills. The creative and innovative teaching and assessments utilized in such courses have increased the popularity of these courses over recent years and have resulted in more students from various faculties enrolling in these courses every semester.

\section{ASSESSING LITERARY COMPETENCIES, MULTIMODAL LITERACIES AND ENTREPENEURIAL SKILLS}

In the following section, an innovative assessment in a UKM literature course that develops multimodal literacies and entrepreneurial skills in students will be discussed in further detail. The execution of the literary merchandise design 
assessment for the Critical Appreciation course will be explained and the merchandise designs created by the students will be analyzed to demonstrate the literary competencies, multimodal literacies, and entrepreneurial skills the students have developed and demonstrated through the assessment. The multiple modes of meaning analyzed in the students' assessments are visual and spatial modes, linguistic modes, gestural modes, audio modes, and technical modes which include digital elements as well (Periasamy, Gruba, and Subramaniam 152). According to Boyles, skills such as creative and critical thinking, innovation, reflective thinking, initiative, communication, collaboration skills, problem solving are shown to be indicative of an individual's entrepreneurial competencies and abilities (45). Thus, the students' assessment output will be analyzed, and the different entrepreneurial skills they have demonstrated will be identified and discussed.

\section{LITERARY MERCHANDISE DESIGN ASSESSMENT}

The Literary Merchandise Design assessment was designed for the Critical Appreciation course offered at Faculty of Social Sciences and Humanities, UKM. The course is offered as a 3 -unit elective liberal (CITRA) course under the language, communication, and literacy domain for students across all faculties in the university. The CITRA or liberal studies program at UKM is designed to help produce well-rounded and holistic graduates. Therefore, all students are strongly encouraged to enroll in courses across a range of disciplines and faculties outside their own fields of study.

The Critical Appreciation course is conducted over a fourteen-week semester, and is made up of students from different faculties and year levels. As an introductory literary studies course, the course introduces students to different genres of literary and non-literary texts and provides the students with the opportunity to develop the various skills from the texts from a critical perspective, taking into account socio-cultural, economic, and political issues that shape the texts. In this paper, the assessment discussed was assigned to the group of students who voluntarily enrolled in the course, which is made up of first, second, and third year undergraduates from various faculties and departments across the university including Education, Science, Social Sciences and Humanities, and Economics faculties.

The students were briefed about all the assessments for the course, including the merchandise design assessment at the beginning of the semester, with additional information and consultation provided on the assessments throughout the fourteen-week teaching period in the semester. The students were tasked to 
complete the merchandise design assessment to demonstrate their understanding and knowledge of a literary text introduced in the course. Instead of testing the students' understanding of the play in the form of a traditional assessment such as an essay or quiz, the literary merchandise assessment was designed so that students can demonstrate their understanding of a play in a unique and original way that would also help them develop multimodal literacies and entrepreneurial skills and mind-sets. Students were encouraged through this assessment not to merely memorize and regurgitate the play via rote learning but to display their critical understanding of the text in a creative, original, and practical form. This was done so that students, especially those from non-language and humanities departments, would realize the practical and current relevance of literature in everyday contexts.

\section{William Shakespeare's Macbeth Merchandise Design}

The students were introduced to William Shakespeare's Macbeth during the second half of the semester from Week 8 onwards. It was the first time for the majority of the students to be formally introduced to a Shakespearean play. In line with the holistic, multimodal approach in the teaching and learning of the course, for over a period of five weeks, students were given input on the play Macbeth, via lectures and tutorial activities. These activities included reading aloud, mind maps, and dramatizations of various scenes, in class analyses and discussions of themes and issues, and viewing of a film adaptation and a live performance of the play to enhance the students' understanding of the play.

After having completed several of these multimodal tutorial activities to increase the students' understanding of Macbeth, students were asked to form groups of 3-4 members and were tasked to design a product or merchandise based on the play. Examples of products designs students could choose to work on were T-shirts, stationery, key chains, and even furniture. However, students were given the autonomy and creative freedom to design any product of their choice. The task required that the merchandise designed by the students be original in design and be inspired by Macbeth.

Students were strongly encouraged to incorporate symbols, colors, character names, and excerpts from Macbeth in their designs, but they would need to be able to critically justify the selection of these aspects in their design to demonstrate their literary competency, i.e. their comprehension of the play through an understanding and awareness of the semiotic, linguistic, sociocultural, historical elements that make up the play (Hapsari 30-31). In designing the merchandise, students were also asked to think about the group of consumers that the merchandise would be 
targeted towards and the estimated cost of the product if it was to be produced to enhance their financial literacy and entrepreneurial mind-set. Students had about five weeks in total to work on this assignment in their groups.

In Week 13, as the culmination of this assessment, students were asked to pitch and promote their designs to the lecturers and their course mates in an oral presentation using appropriate visual images to explain their designs. This is to develop their linguistic abilities and increase their confidence in public speaking. In keeping with the entrepreneurial theme of the assessment, during the merchandise pitch, students had to introduce their merchandise and explain to their peers and lecturers their choices and decisions in all the aspects of their design including the choice of text, color, images, visuals and shape.

In their pitching sessions, students had to conceptualize and prepare the style and approach of their pitch, therefore applying creative, innovative thinking. They also had to prepare visual slides and aids to further explain their designs which helped them improve their visual, linguistic, and technical/digital literacy skills. To provide an experience of focus group marketing technique, students were asked to seek input from their peers on their design and answer any question or doubt their peers might have on their presented merchandise. This allowed the students to enhance their analytical problem solving skills and to develop confidence. Throughout the entire process of the assessment, from the conceptualization and design of the product to the preparation of the presentation, the groups of students had consultations with the lecturers to seek guidance or clarification on the task.

The assessment for the Macbeth merchandise design assignment was done based on the following criteria: literary competence, multimodal literacy, and entrepreneurial skills. The assessment took into account the product designed by the students and the explanation they provided on the product's concept, design, significance to the original text, and commercial value presented during the pitching sessions. Students were graded on their ability to demonstrate their critical appreciation and intrinsic understanding of essential literary elements in Macbeth such as characterization, plot, setting, theme, genre, symbols, and metaphors in the design of their merchandise. Students were also awarded marks for displaying visual, technical, and digital literacies, as well as knowledge of social and historical context of the play. Last but not least, students were graded based on the originality, creativity, and innovativeness of their merchandise concept and design. Students were also awarded marks for presenting during the pitching session, their thoughts and ideas about the marketing, branding, and financial aspects of the merchandise such as target audience, price, and other marketing strategies. 


\section{ANALYSIS OF STUDENTS' MACBETH MERCHANDISE DESIGNS.}

In this section, selected merchandise designed by the students will be analyzed and discussed to demonstrate the literary competencies, multimodal literacies, and entrepreneurial skills that the students have showcased through this assignment. Firstly, there was a great display of creativity and originality showcased by all students in this task. This is attributed to the learner autonomy that was given to the students in the task assignment. Creativity and originality were evident from the wide range of Macbeth-inspired merchandise. Among the merchandise designed by the students included mugs, scarfs, T-shirts, bookmarks, pens, watches, and mobile phone casings. By not limiting the students' choices in product design, the assessment allowed the students to be creative and imaginative in their choice of merchandise or product. As a result, the students created a diverse range of merchandise.

For the purpose of this study, four merchandise designs-a mug, two T-shirts, and a scarf-will be discussed to demonstrate the multimodal literacies and entrepreneurial skills that the assessment helped develop in the students.

\section{Macbeth His and Hers Couple Mug}

The Macbeth Couple Mug was designed by one group of students from the Critical Appreciation course in 2017. The merchandise's target consumers were couples in love and are fans of literature.

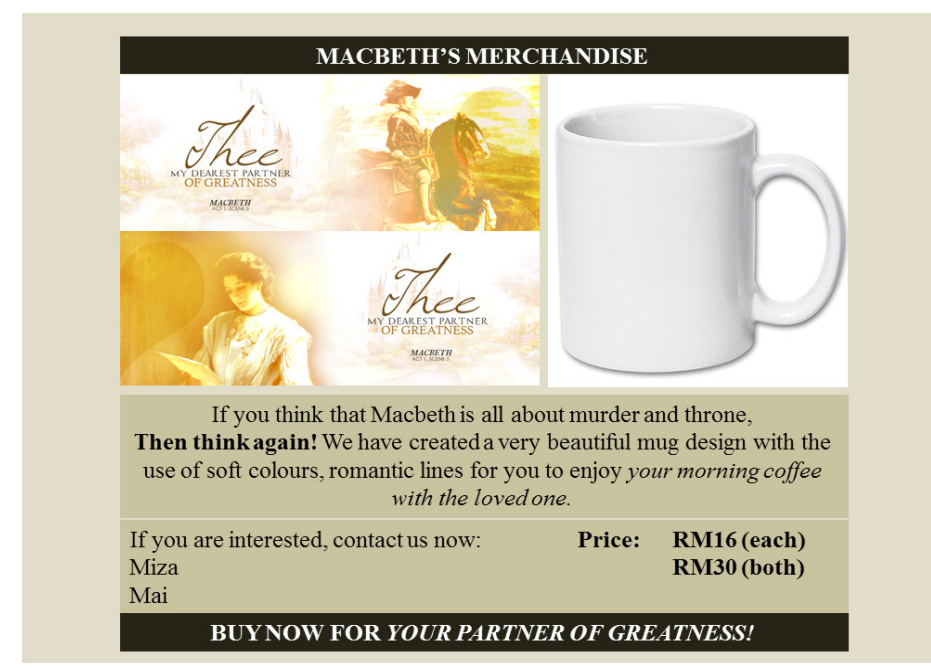

Fig. 1. Macbeth-inspired His and Hers Couple Mug 


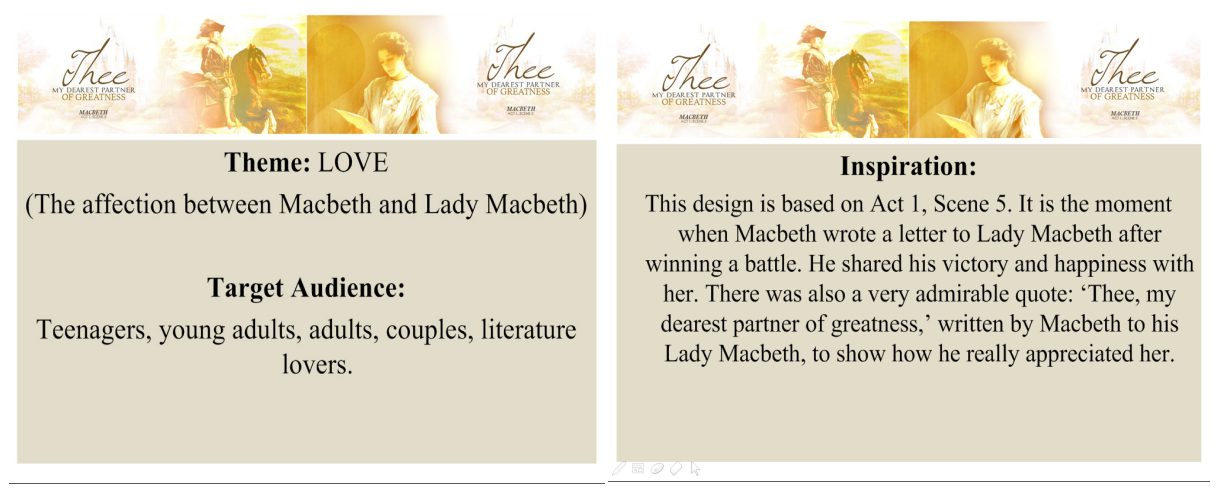

Fig. 2. Couple Mug Theme, Target Audience and Inspiration

In pitching this merchandise to their peers, the students explained that although Macbeth was a tragedy, they had chosen to focus on the romantic relationship that was found in the play. The students explained that in spite of all the sinister events that surrounded them, the characters Lord and Lady Macbeth still demonstrated an affectionate and committed relationship and loved each other deeply. To further promote and convince potential customers of their product, the students showed their linguistic abilities in the description of their product: "for you to enjoy your morning coffee with the loved one," as seen Figure 1.

In Figure 2, presented during their product pitching session, the students' explanation of their product and concept demonstrate their deep and critical understanding of the characterizations and themes in Macbeth. The decision to create love-themed merchandise inspired by a tragic play also shows innovation and creativity, as well as originality on the part of the students. As a tragic play, most people would focus on the negative aspects of Macbeth such as the murder, betrayal, jealousy, and greed found in the play. However, the students who designed the mug have shown their ability to think out of the box and focus on a more positive aspect of the play which others may have side-lined. In doing this, the students have demonstrated the ability to be unconventional and divergent in their thought process, often valued as entrepreneurial skills. Furthermore, the students have shown enterprising potential in taking risks by means of identifying couples and lovers as the target market of a product inspired by a tragedy like Macbeth. The students have demonstrated entrepreneurial tendencies by showing that they can take inspiration from any source and convert it into a potentially profitable product. 


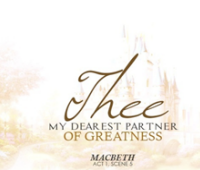

쎰다표

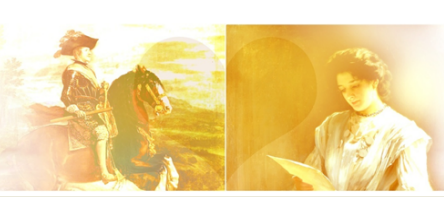

\section{Critical Aspects}

Why half love at the end of each design?

In this case, this is a couple mug where the half design of love, if both mugs are put together, it will form a true love.

Why yellow + brown is the main theme (colour) for this design? Yellow is a very meaningful colour. It is a symbol of sovereignty. It also shows happiness. However, yellow also means cowardice. Just like how Macbeth was scared to be haunted by his own sins, he kept murdering other innocent souls just to keep his secret concealed. This shows that Macbeth could not be responsible towards what he had done. Next, in some countries, yellow is for mourning. This really fits The Tragedy of Macbeth where at the end of the play, both Macbeth and Lady Macbeth were separated by death. Other than that, yellow can be a soothing colour to the eyes. Thus, looking at the yellow mug while your morning coffee can be a great day starter.

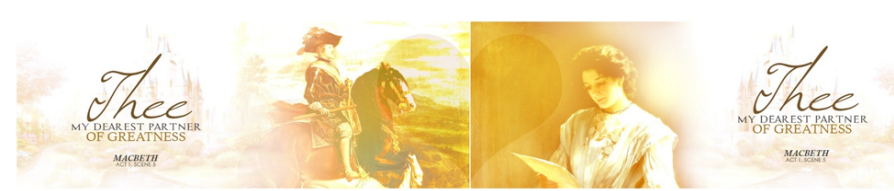

\section{Critical Aspects}

\section{Why a man with a horse?}

Both pictures of a man with a horse and of a woman with a love letter are actually complementing the real act (Act 1, Scene 5). In that act, after winning the battle, Macbeth sent a letter to his wife. We decided to pick a man on his horse is because we want to portray that Macbeth is going back home to his wife with pride and joy. At the same time, we want to show that he could not wait to see his wife and how he longed for her. Lady Macbeth, on the other hand, was waiting for his return.

Fig. 3. Critical Justification of Couple Mug Design

Figure 3 shows the visuals used in the students' merchandise design pitch to justify their creative choices in the design of the Macbeth-inspired His and Her mug. The students explained the practical applications of the "half love" design in the mug. Students also justified the choice of the yellow and brown colors chosen for the design by explaining the connotations and the meanings of the colors based on cultural and visual conventions. Through these explanations, the students demonstrated high levels of visual literacy and critical thinking. Also, in keeping with the literary analysis taught in the course, students were able to link the choice of the color with the genre and tone of the play, thus demonstrating literary competence. Next, the students explained how the choice of images used in the design was inspired by Act 1, Scene 5 of Macbeth.

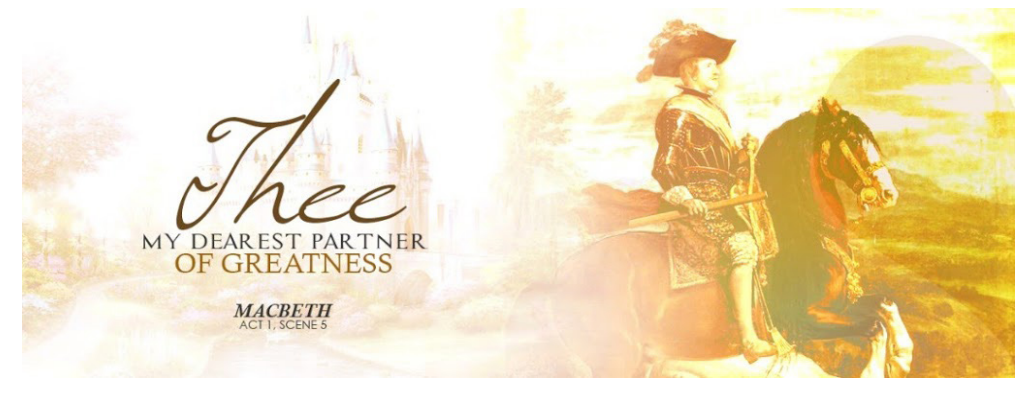

Fig. 4. His Couple Mug Design 
The students explained that the man riding a horse symbolized Lord Macbeth on his triumphant return home after the battle and the lady with the letter symbolized Lady Macbeth, waiting for the return of her beloved husband and reading the love letter he had written to her.
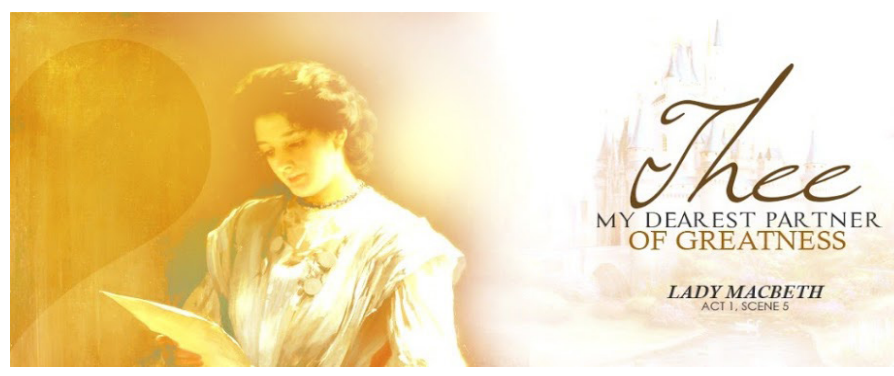

Fig. 5. Hers Couple Mug Design

Additionally, the students explained why they used an image of a castle in the mug, thus demonstrating their knowledge of the play's setting and plot. This showed the students' in-depth understanding of the play and the literary devices used it.

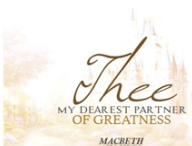

MA뮤표

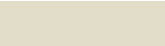

Why castle?

Throughout the play, we can see that their affection towards each other happened only in the castle. Besides, there was never once, Shakespeare wrote about Lady Macbeth went out from the castle. She was in the castle all the time.

Why 'Thee' is different from the other font?

This is to emphasize that 'you' are special. Thee means you. And it is also made into a cursive font is because; those words are found in a love letter. Back then, when people wrote love letter, they would use those kinds of fonts which portray romance.

Fig. 6. Justification of Visual and Linguistic Elements in Mug Design 
The students have shown in Figures 5 and 6 their knowledge of old English terms and the plays' geographical, temporal, and cultural context by using suitable images such as a castle and a horse in the design. Upon doing this, they have demonstrated literary competence of Macbeth in their understanding of the linguistics, historical, and sociocultural elements of the play. The students also showcased critical thinking and visual literacy in justifying their selection of the font for the word "Thee" and explaining why they had chosen to differentiate "Thee" from the other words. Knowledge and awareness of diverse, global cultures and environments are essential for a successful entrepreneur and for any individual in the twenty-first century context, and the students have certainly demonstrated these skills through their work.

In addition to critically justifying the creative choices in the merchandise design, students had to explain the cost and pricing of the merchandise. This aspect of the students' pitch or oral presentation meant to help them develop financial literacy and hone their entrepreneurial skills. The students explained that they have priced their mug as RM 16 per mug or RM 30 for a complete pair. The students demonstrated that they were financially savvy by providing a discount for the purchase of two mugs. The students explained the cost of the mug and justified the cost by describing its one-of-a-kind original design value. Additionally, the students sought feedback from their peers in the audience on the cost and affordability of the mug in a focus group-like survey. This aspect of the task helped the students develop experience in costing, market survey, marketing, and brand promotion which are all valuable entrepreneurial skills that can help them in their future endeavors.

\section{Macbeth T-Shirt Designs}

In the examples of the Macbeth-inspired T-shirt designs below, students have demonstrated their creative, critical thinking, multimodal literacy, technological literacy, and entrepreneurial skills through the completion of the assessment.

One group, which called themselves the Macduffs, embraced the entrepreneurial spirit of the task and developed a group name inspired by key characters from the play. As seen in the mock posters (see Figure 7) presented during their pitch, students of these two groups displayed knowledge of product sales and marketing, communication competence in rhetoric and all other entrepreneurial qualities by means of advertising the fine quality of the T-shirt fabric, specifying the target customers, and emphasizing its affordable prices. The creation of the poster design, layout, and wordings, where the students have carefully selected colors, fonts, 

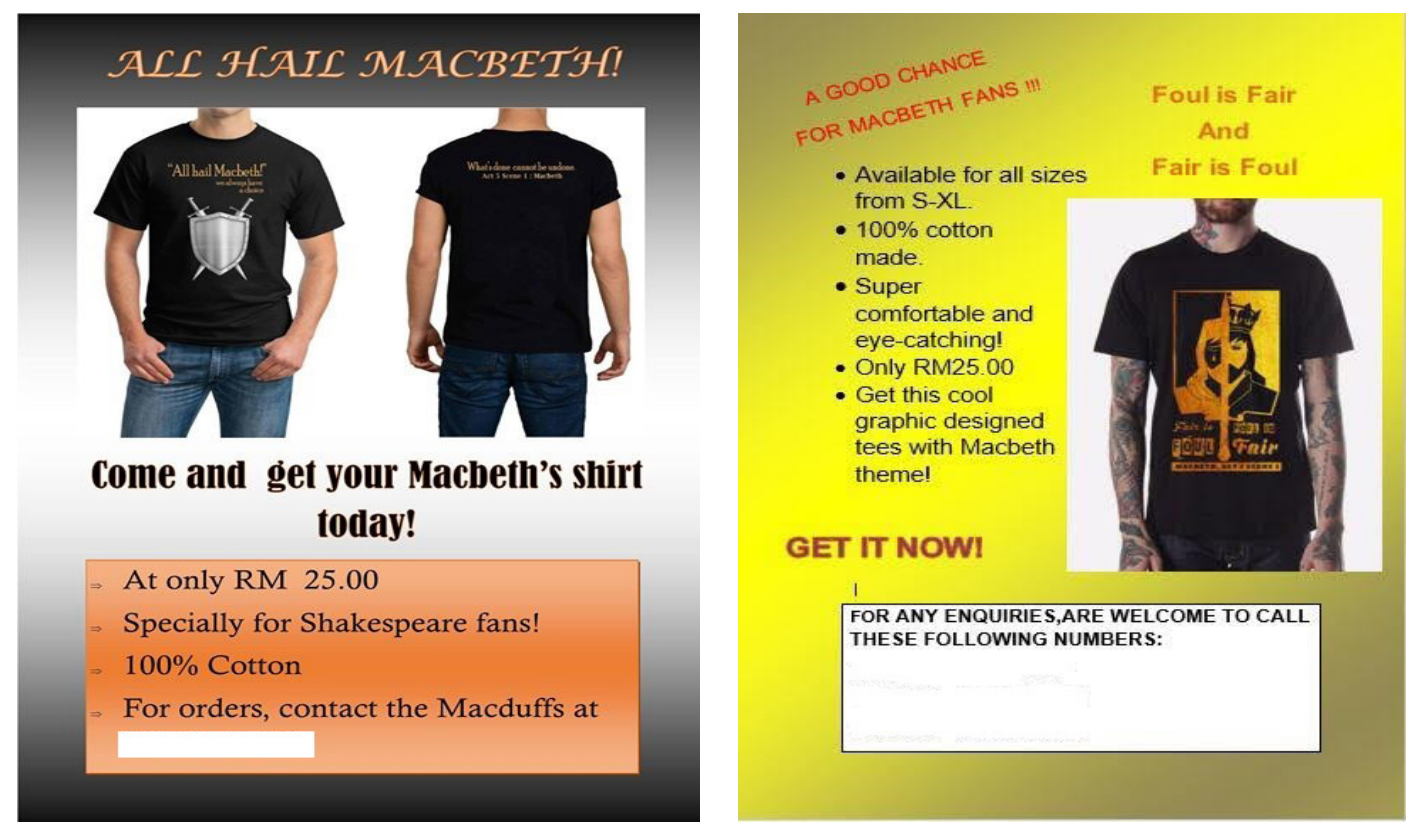

Fig. 7. Macbeth Macduffs and Fair n Foul T-shirt Designs

borders, and slogans, display the students' competencies in visual, spatial, literary, linguistic, and digital literacies.

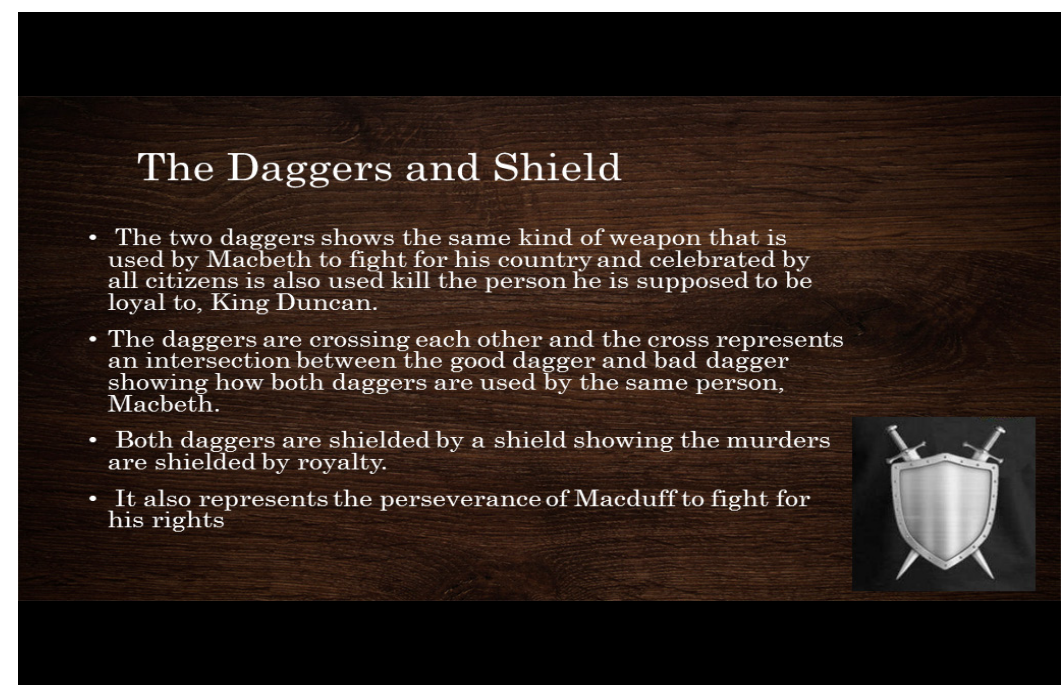

Fig. 8. Macbeth Macduffs T-shirt Symbols Critical Justifications 
The slide above presented by the Macduffs group in their pitch critically explains the group's choice of symbols used in the T-shirt design. In doing this, the students demonstrated in-depth understanding of the play and its theme, plot and characters, especially of Lord Macbeth and his duality and ambitions to attain power. Students also displayed knowledge of the literary and visual elements in the explanation of what the symbols represent. The ability to identify and understand a literary symbol in the text, create a visual representation of it and justify the elements of the visual design and components demonstrates critical and analytical thinking skills on the part of the students.

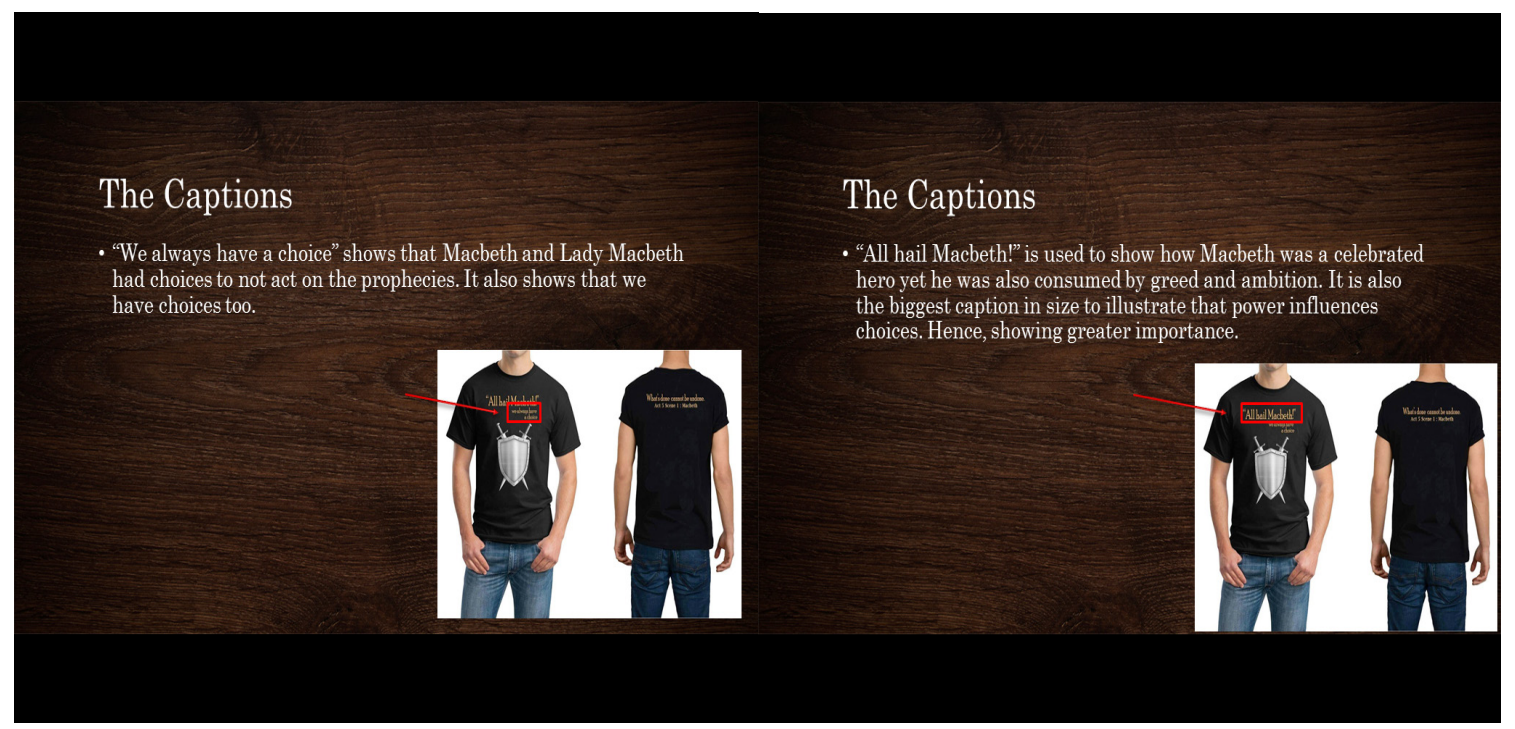

Fig. 9. Macbeth Macduffs T-shirt Captions and Critical Justifications

This group of students also displayed critical and reflective thinking through the explanation the caption that they included at the back of the T-shirt. They explained that the captions are meant to show that like the characters in the play, we too, have the power to make the right or the wrong choices and decisions in life. The captions also show the high level of literacy of the linguistic mode. In being able to connect the literary texts to real people and current issues, students displayed maturity and logical and reflective thinking abilities.

Like the Macduff group, the group that designed the Fair n Foul design also demonstrated in-depth understanding of the play and critical thinking. Both groups displayed great technical and visual literacy in the striking designs of their T-shirts. Every element in the design, its color, image, symbol, and caption was explained and critically justified and linked to their understanding of Macbeth. In their successful 


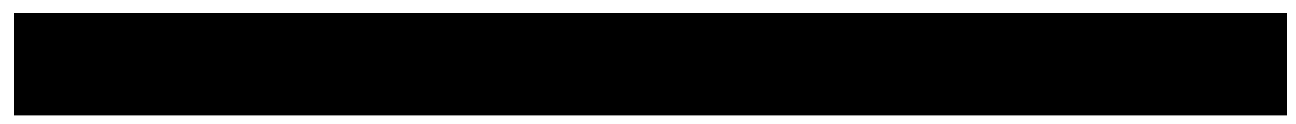

MERCHANDISE: GRAPHICTEE

- Duality represents the struggle between Macbeth's conscience (left) and his ambition (right).

- The tear on the left side of Macbeth represents his humanity and conscience as a man, on the right shows Macbeth as a tyrannical king, without compassion and mercy.

- Gold can represent either the royalty that Macbeth wanted so badly or the greed that consumes him.

- Black coloured shirt, represents power and authority, and also evil and death.

- Separating these 2 sides of Macbeth could be a sword or a dagger: sword represents his identity as the patriotic Thane of Glamis, fighting for his country; dagger represents his betrayal to King Duncan by murdering him.

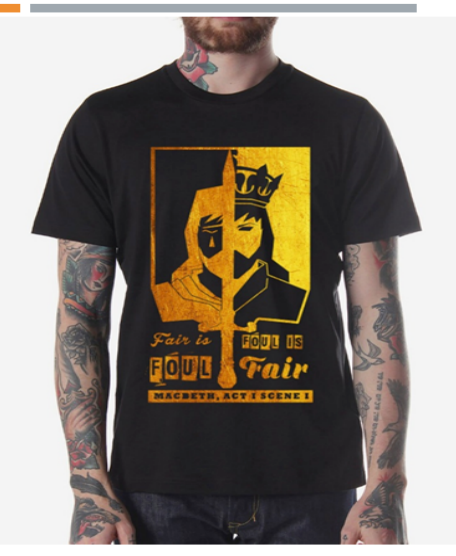

Fig. 10. Macbeth Fair n Foul T-shirt Critical Justifications

and impressive completion of the Literary Merchandise Assessment, the students demonstrated the literary competencies, multimodal literacy, and entrepreneurial skills.

\section{Macbeth Scarf Design}

In the scarf design seen in Figures 11 and 12, students again demonstrated literary competence in their knowledge of the historical and cultural context of the play. Tartan is synonymous with Scottish culture and regarded as a cultural icon of Scotland. In choosing the tartan design pattern for the scarf, the students injected the Scottish cultural element in their merchandise to reflect the play's geographical and cultural setting. This shows awareness of global culture and trends which are useful entrepreneurial attributes.

Also evident in Figure 11 is the use of rhetoric language in the poster to convince potential customers of the quality and worth of their merchandise. Students drew attention to the price of the scarf by using phrases like "as low as." In addition to vouching for the quality of the fabric, "100\% wool," they also focused on their target audience, "Shakespeare Fans and Literature Enthusiasts." These elements in 


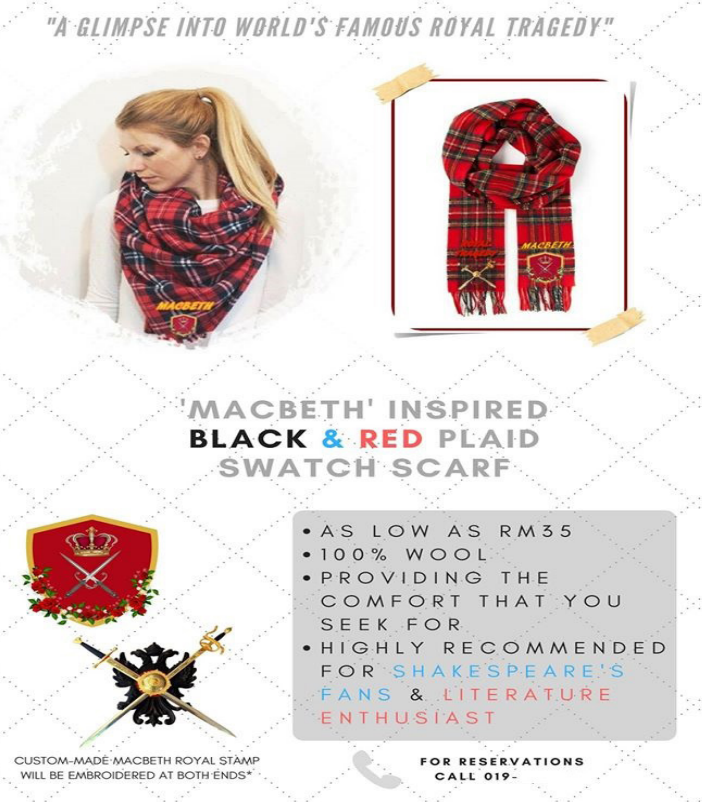

Fig. 11. Macbeth Plaid Swatch Scarf

the merchandise promotional flyer demonstrate that these students are developing business and financial savviness and entrepreneurial mindsets.

In designing the scarf, the students also included a crest or coat of arms, displaying their understanding of Macbeth and Scottish family and clan traditions. The design of the crest displays creativity, innovation, and ingenuity. While branding their creation with the Macbeth brand and identity, the students also enhanced the aesthetic and commercial value of their merchandise with the inclusion of the crest. As seen in Figure 12, students identified every element in the crest and related it to symbols that can be found in the play and Scottish culture. This demonstrates the students' critical understanding of the play and the ability to transfer elements found in the play into an aesthetically pleasing and commercially viable product. These are indeed skills that would be considered to be entrepreneurial. The students were able to fully comprehend the play in its written form (linguistic mode) and recreate elements of the play including its settings, characters, symbols, and themes into a visual and digital form. 

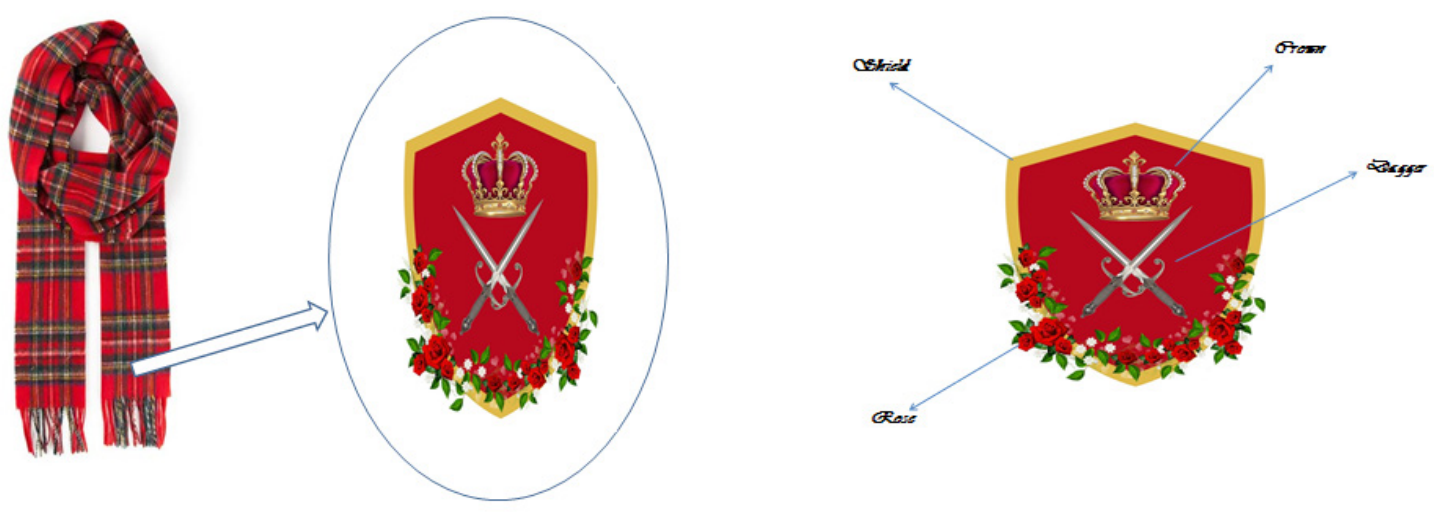

Fig. 12. Macbeth Scarf Crest

\section{LITERARY COMPETENCIES, MULTIMODAL LITERACIES AND ENTREPRENEURIAL SKILLS FROM ALTERNATIVE LITERARY ASSESSMENTS.}

The analysis of the merchandise designs produced by the students has revealed how teaching and learning in literature can develop skills that are useful and relevant in the twenty-first century. While teaching and assessments for literature in the past focused on reading, writing, and the understanding of texts with focus on developing language, linguistic, and literary competencies, this study has shown how literature can also be used to develop visual, spatial, audio, gestural, and technical/digital literacies.

The students have demonstrated in their successful completion of the assessment their engagement with multiple modes of learning although the original text of the play, Macbeth, is in the written form (linguistic mode). The ability to consume and understand texts in one mode and represent and reproduce it in other modes demonstrates creative, innovative, and critical thinking abilities. The assessment has therefore allowed students to engage in different modes of learning even though they had to read the play and focus on developing their literacy of the linguistic mode in the beginning. The assessment has shown a current and alternative approach to assessing students' understanding of literary text and developing the students' literary competencies, multimodal literacy, and entrepreneurial skills.

Creativity and originality are key components in the assessments of the students' designs, and the students were able to showcase these qualities in their output as seen in the previous sections. Another important criterion for the assessment is that it promotes critical thinking and allows students to engage with and apply the 
literary text in an original, innovative, and unconventional manner. In the pitching of their designs, the students were also able to critically justify their creative choices in the assessments and relate these choices to the themes and issues found in the literary text. The students also showed the ability to work with their peers and discover their roles within a team which has been an important aspect of the assessments. The assessment is designed so that students are able to engage in collaborative brainstorming, decision making, and problem solving in order to prepare for the real world. This aspect is also incorporated to help students sharpen their interpersonal skills and develop respect for other members in the group.

Technology and digital tools are important in the teaching of the course to keep up with the changes in the teaching and learning styles in the twenty-first century. More importantly, digital tools are used to demonstrate that literature is not only confined to the linguistic mode. In order to enable students to engage with digital technology, students were encouraged in the assessment to use digital tools in the conceptualization and presentation of their designs. As digital natives, the students demonstrated their ability to employ technology and digital tools effectively in their merchandise designs, promotional flyers, and pitching slides.

\section{Student Feedback}

Students who completed this assessment as part of the Critical Appreciation course provided reflective feedback on the assessment. Students revealed that the task indeed helped them gain entrepreneurial mindsets and skills. One student commented that she learned "to look deeper into a certain story and pick out elements that can be related by the consumers rather than only using the word 'Macbeth'.... we learned to put ourselves in the place of a buyer to come up with a product that can attract the consumer." Students also revealed that they found the assessment unique, innovative, and fun which enhanced their learning experience: "The Macbeth merchandise design assignment was a fun task to do and it was a different form of evaluation for students. Traditionally, the most common tool for evaluation is exams and quizzes. The Citra course of Critical Appreciation completely flipped the table over on the students' stereotypical notion on the manner of evaluation."

Students revealed that the pitching element of the assessment was helpful in developing entrepreneurial skills: "this assignment helped me to develop my entrepreneurial skills because we were required to pitch our ideas to the lecturers and the rest of our friends in the class. It was so much fun because we had the opportunity to receive important constructive feedback from the class. The pitching 
session was made more exciting when we got to see merchandise ideas from the other groups." As mentioned by another student, the task helped them understand the literary text better and developed creativity and originality: "In order to create an original piece, we knew that searching for an idea which might be overlooked by most people was crucial. So, we reread the text. We also did a lot of reading regarding Macbeth and symbolism. We watched Macbeth play and went through different opinions from random websites that discussed about Macbeth." A final revelation by a student reinforced the success of this task in encouraging entrepreneurial tendencies: "we had never thought of commercializing our merchandise project. In fact, we thought it was impossible. After getting encouragement and positive feedback from lecturers and other classmates, I started to think differently and continuously seek for opportunity to sell my artwork." Students' feedback on the assessment has shown that they found it to be a productive and effective one in increasing their literary competencies and multimodal literacies, and also in developing entrepreneurial skill sets. Students' reflections also reveal that they found the task enjoyable which enhanced their experience of learning literature.

\section{CONCLUSION}

This paper has shown the ability of literature courses in developing twenty-first century skills in university students from different academic departments and faculties. The use of innovative alternative assessments was able to develop skills and competencies related to multimodal literacies, entrepreneurship, communication, collaboration, teamwork, and more. Students had first-hand experience of a literature course that enabled them to engage with different literacies and technology and to learn about various cultures, time periods, peoples, ideas, and sociopolitical and cultural issues.

The assessments that the students undertook showed them the ability of literary texts and narratives to inspire creativity and innovation, develop entrepreneurial skills, and be a potentially lucrative and financially viable asset for students of all academic backgrounds. The innovative assessment promoted collaboration among students of different strengths, abilities, intelligences, and skills sets and was instrumental in creating an enjoyable learning experience of a literature course for all students. The experiences and skills gained by students through the course changed their perceptions about literature and its relevance as a field of knowledge in the twenty-first century. Students from the arts, commerce, and science departments were able to experience the holistic education that can be gained through literary studies. 
The paper has shown how assessments in literature courses can be designed to be more holistic and current in knowledge and skills development. It has provided a glimpse into the potential that literary studies has in developing various skills, knowledge, and abilities that help shape intellectual, multi-skilled, and holistic individuals, showcasing literature as a dynamic and relevant force in the twentyfirst century. 


\section{Acknowledgement}

This research is made possible through a university funded grant by the National University of Malaysia (GGPM-2016-075). 


\section{Works Cited}

Bassnett, Susan. "Literature Teaching in the Twenty-First Century: A Hopeless Endeavour or the Start of Something New?" The Cambridge Quarterly, vol. 34, no. 3, 2005, pp. 203-212.

Boyles, Trish. "twenty-first Century Knowledge, Skills and Abilities and Entrepreneurial Competencies: A Model for Undergraduate Entrepreneurship Education." Journal of Entrepreneurship Education, vol. 15, 2012, pp. 41-55.

Chin, Ee-Loh, Suzanne Choo, and Catherine Beavis. "Globalizing Literature Education in the Asia-Pacific. Remapping the boundaries." Literature Education in the Asia-Pacific: Policies, Practices and Perspectives in Global Times, edited by Ee-Loh Chin, Suzanne Choo, and Catherine Beavis, Routledge, 2018, 1-13.

Jia, Wei Lim. "Desired Student Response and its potential in Forms of English Literature Education in Malaysia." Literature Education in the Asia-Pacific: Policies, Practices and Perspectives in Global Times, edited by Ee-Loh Chin, Suzanne Choo, and Catherine Beavis, Routledge, 2018, pp.120-137.

Dass, Rozita. "Literature and the twenty-first Century Learner." Procedia-Social and Behavioural Sciences, vol. 123, 2014, pp. 289-298.

Director General of Education Malaysia. Penukaran Teks Baharu Komponen Sastera (KOMSAS) Dalam Mata Pelajaran Bahasa Inggeris Tingkatan 2 dan Tingkatan 5 Mulai Tahun 2016. Surat Pekeliling Ikhtisas Kementerian Pendidikan Malaysia Bilangan 11 Tahun 2015, 29 Dec. 2015, https://www.moe.gov.my/index.php/my/pekeliling/ pekelilling-ikhtisas/category/kurikulum/5. Accessed 8 June 2018.

Griffin, Patrick, and Esther Care, editors. Assessment and Teaching of twenty-first Century Skills: Methods and Approach. Springer, 2015

Hapsari, Astri. "Literary Competence for the Teaching of Literature in Second Language Educational Context." Journal of English and Education, vol. 5, no. 1, 2011, pp. 29-36.

Kramsch, Claire, and Olivier Kramsch. "The Avatars of Literature in Language Study." The Modern Language Journal, vol. 84, no. 4, 200o, pp. 553-573.

Lowden, Kevin, Stuart Hall, Dely Elliot, and Jon Lewin. Employers' Perceptions of the Employability Skills of New Graduates. University of Glasgow SCRE Centre and Edge Foundation, 2011.

Roche, Mark W. "Why Literature Matters in the twenty-first Century." Notre Dame Sites, 2004, http://sites.nd.edu/community-engagement-faculty-institute/files/2012/05/ Roche-Mark.-Why-Literature-Matters-Alumni-Talk.pdf. Accessed 5 June 2018.

Periasamy, Melissa Shamini, Paul Gruba, and Ganakumaran Subramaniam. "A Multimodal Literary Analysis of a Television Commercial." 3 L: Language, Linguistics and Literature, vol. 21, no. 3. 2015, pp. 51-164.

Pillai, Shanthini, and Ravichandran Vengadasamy. "Developing Understanding and Appreciation of Literature and Critical Reading Concepts through Multimodal Approaches." Malaysian Journal of ELT Research, vol. 6, no. 1, 2010, pp. 133-166. 
Sidhu, Gurnam Kaur, Chan Yuen Fook, and Sarjit Kaur. "Instructional Practices in Teaching Literature: Observations of ESL Classrooms in Malaysia." English Language Teaching, vol. 3, no. 2, 2010, pp. 54-63.

Siti Norliana Ghazali, Roszainora Setia, Chittra Muthusamy, and Kamaruzaman Jusoff. "ESL Students' Attitude toward Texts and Teaching Methods Used in Literature Classes." English Language Teaching, vol. 2 no. 4, 2009, pp. 51-56.

Sivapalan, Subarna, and Ganakumaran Subramaniam. "The Incorporation of Literature in the English Language Program for Engineering Students: Learner Interest and Perception." 3 L: Language, Linguistics, Literature, vol. 14, 2008, pp. 45-73.

Subramaniam, Ganakumaran. "Teaching Literature: Exploring Theory and Practice." Approaches to Teaching Literature: Theory and Practice, edited by Ganakumaran Subramaniam, Sasbadi Sdn. Bhd., 2007, pp. 1-22.

Sullivan, Michael. "Changing the 'Success Narrative': English Literature Can Help Broaden Hong Kong Students' Perception of Education." Literature Education in the AsiaPacific: Policies, Practices and Perspectives in Global Times, edited by Ee-Loh Chin, Suzanne Choo, and Catherine Beavis, Routledge, 2018, pp 60-72.

Talentcorp. "Matching Talents to Jobs. Trends in Graduate Employability." myStarjob.com, 9 Aug. 2014, http://mystarjob.com/articles/story.aspx?file=/2014/8/9/mystarjob_career guide/15049373\&sec=mystarjob_careerg. Accessed 15 Mar. 2018.

The National Curriculum in England: Key Stages 1 and 2 Framework Document, https:// assets.publishing.service.gov.uk/government/uploads/system/uploads/attachment_ data/file/425601/PRIMARY_national_curriculum.pdf. Accessed 14 June 2018.

Yusof, Noraini Md. "E-Methods in Literary Production: Integrating E-Learning in Creative Writing." 3 L: Language, Linguistics, Literature, vol. 14, 2008, pp. 127-148. 